\title{
Nós sonhamos com nós mesmos
}

\author{
Daniela Osvald Ramos
}

Henri Michaux nasceu em 24 de maio de 1899, em Namur, Bélgica, e morreu em 1984, com 85 anos, em Paris. Poeta, pintor e viajante, trabalhou também durante a época do Surrealismo, embora essa informação sirva somente para situar sua produção. Michaux evitou ser rotulado de surrealista ou de qualquer outra coisa. Com uma obra extensa, tanto na poesia quanto nas artes plásticas, seu relato de maior sucesso como viajante foi Um bárbaro na Ásia ${ }^{1}$, uma espécie de diário de andanças pelo continente.

Também fez experiências com a alteração da consciência, como desenhos e poemas sob e sobre a influência de drogas alucinógenas, em especial a mescalina. Esse não foi seu principal mote, mas é um dos dados mais divulgados sobre a vida do poeta. "Escrita livre", "temperamento particular", consciente da solidão intrínseca da condição humana e por vezes irônico e sarcástico; apesar desses índices, a melhor maneira de entrar em contato com Michaux, claro, é lendo-o, mas não só: viver o instante da leitura, o momento, que nunca é preso por palavras. Afinal, segundo ele, as palavras chegam "mais tarde, sempre mais tarde".

As versões dos poemas em português foram elaboradas a partir da edição argentina Antología Poética, 1927-1986, edição bilíngüe

1 Uma das raras, senão única obra do autor, editada no Brasil pela Nova Alexandria. 
da Adriana Hidalgo Editora, com seleção e tradução de Silvio Mattoni, para o espanhol. Em "Le jour, les jours, la fin des jours" respeitei a métrica do francês.

Agradeço imensamente os comentários e sugestões de Virna Teixeira e Annita Costa Malufe.

Labyrinthe, la vie, labyrinthe, la mort

Labyrinthe sans fin, dit le Maître de Ho.

Tout enfonce, rien ne libère.

Le suicide renaît à une nouvelle souffrance.

La prison ouvre sur une prison

Le couloir ouvre un autre couloir:

Celui qui croit dérouler le rouleau de sa vie

Ne déroule rien du tout.

Rien ne débouche nulle part

Les siècles aussi vivent sous terre, dit le Maître de Ho.

Labirinto, a vida, labirinto, a morte

Labirinto sem fim, diz o Mestre de Ho.

Tudo afunda, nada libera.

O suicida renasce para um novo sofrimento.

A prisão dá em uma prisão

O corredor dá em outro corredor: 
Aquele que crê desenrolar o rolo de sua vida

Não desenrola nem um pouco.

Nada desemboca em lugar algum

Os séculos vivem também debaixo da terra, diz o Mestre de Ho.

\section{Ma Vie}

Tu t'en vas sans moi, ma vie.

Tu roules,

Et moi j'attends encore de faire un pas.

Tu portes ailleurs la bataille.

Tu me déserts ainsi.

Je ne $t^{\prime}$ ai jamais suivie.

Je ne vois pas clair dans tes offres.

Le petit peu que je veux, jamais tu ne l'apportes.

A cause de ce manque, $j^{\prime}$ a aspire à tant.

À tant de choses, à presque l'infini...

À cause de ce peu qui manque, que jamais tu n'apportes. 


\section{Minha Vida}

Tu partes sem mim, minha vida.

Tu rodas,

E eu ainda espero dar um passo.

$\mathrm{Tu}$ levas a batalha para outro lugar.

Tu me desertas assim.

Eu nunca te segui.

Não vejo claramente tuas ofertas.

O tão pouco que desejo, tu jamais trazes.

Por causa desta falta, anseio a tanto.

A tanta coisa, quase ao infinito...

Por causa deste pouco que falta, que tu jamais trazes.

J'étais un foetus.

Ma mère me réveillat quand il lui arrivait de penser à M. de Riez.

En même temps, parfois se trouvaient éveillés d'autres foetus, soit de mères battues ou qui buvaient de l'alcool ou occupées au confessional.

Nous étions ainsi, un soir, soixante-dix foetus qui causions de ventre à ventre, je ne sais trop par quel mode, et à distance.

Plus tard nous ne sommes jamais retrouvés.

J'étais une parole qui tentait d'avancer à la vitesse de la pensée. Les camarades de la pensée assistaient.

Pas une ne voulut sur moi tenir le moindre pari, et elles étaient bien là six cent mille qui me regardaient en riant. 
Cadernos de Literatura em Tradução, n. 9, p. 193-208

Eu era um feto.

Minha mãe me despertava quando chegava a pensar no Senhor de Riez.

Ao mesmo tempo, às vezes outros fetos acordavam, filhos de mães espancadas ou que bebiam álcool ou ocupadas no confessionário.

Uma noite, éramos em torno de setenta fetos que conversavam de ventre a ventre, e à distância, não sei muito bem de que maneira.

Nunca mais voltamos a nos encontrar.

Eu era uma palavra que tentava avançar à velocidade do pensamento.

As companheiras do pensamento assistiam.

Nenhuma quis fazer a menor aposta em mim, e elas eram mais de seiscentas mil, que me observavam, rindo. 


\section{Le jour, les jours, la fin des jours}

Sans qu'ils parlent, lapidé pour leurs pensées

Encore un jour de moindre niveau. Gestes sans ombres

À quel siècle faut-il se pencher pour s'apercevoir?

Fougères, fougères, on dirait des soupirs, partout, des soupirs

Le vent éparpille les feuilles détachées

Force des brancards, il y a dix huit cent mille ans on naissait déjà pour pourrir, pour périr, pour souffrir

Ce jour, on en a déjà eu de pareils

quantité de pareils

jour ou le vent s'engouffre

jour aux pensées insoutenables

Je vois les hommes immobiles

couchés dans des chalands

Partir.

De toute façon partir.

Le long couteau du flot de l'eau arrêtera la parole. 


\section{O dia, os dias, o fim dos dias}

Sem que eles falem, lapidado por seus pensamentos

Mais um dia de menor nível. Gestos sem sombras

A qual século é preciso se inclinar para perceber?

Samambaias, samambaias, diríamos suspiros, por toda parte, suspiros

O vento espalha as folhas soltas

Força das macas, há cento e oitenta mil anos já se nascia para apodrecer, para perecer, para sofrer

Este dia, quando éramos semelhantes

quantidade de semelhantes

dia em que o vento se traga

dia de pensamentos insustentáveis

Vejo os homens imóveis

deitados nas canoas

Partir.

De qualquer maneira, partir.

A longa lâmina do fluxo d'água deterá a palavra. 
Daniela Osvald Ramos. Nós sonhamos com nós mesmos

\section{Emportez-moi}

Emportez-moi dans une caravelle,

Dans une vieille et douce caravelle,

Dans l'étrave, ou si l'on veut, dans l'écume,

Et perdez-moi, au loin, au loin,

Dans l'attelage d'un autre âge,

Dans le velours trompeur de la neige,

Dans l'haleine de quelques chiens réunis,

Dans la troupe exténuée des feuilles mortes.

Emportez-moi sans me briser, dans les baisers,

Dans les poitrines qui se soulèvent et respirent

Sur les tapis des paumes et leur sourire,

Dans les corridors des os longs, et des articulations.

Emportez-moi, ou plûtot enfouissez-moi. 


\section{Leve-me}

Leve-me em uma caravela,

Em uma velha e doce caravela,

Na proa, ou se quiser, na espuma,

E perca-me, ao longe, ao longe,

No atrelamento de uma outra idade,

No veludo enganador da neve,

No hálito de alguns cães reunidos,

Na reunião extenuada de folhas mortas.

Leve-me sem quebrar, entre beijos,

Em peitos que se erguem e respiram

Sobre tapetes de palmas e seus sorrisos,

Nos corredores dos longos ossos, e das articulações.

Leve-me, ou melhor, enterre-me. 
Daniela Osvald Ramos. Nós sonhamos com nós mesmos

\section{Les Inachevés}

Visage qui ne dit qui ne rit qui ne dit oui ni non.

Monstre.

Ombre.

Visage qui tend,

qui va,

qui passe,

qui lentement vers nous bourgeonne...

Visage perdu.

\section{Os Inacabados}

Rosto que não diz que não ri que não diz sim nem não.

Monstro.

Sombra.

Rosto que se move,

que vai,

que passa,

que lentamente brota em nossa direção...

Rosto perdido. 


\section{Un Tout Petit Cheval}

J'ai élevé chez moi um petit cheval. Il galope dans ma chambre. $\mathrm{C}^{\prime}$ est ma distraction.

Au début, j'avais des inquiétudes. Je me demandais s'il grandirait. Mais ma patience a été récompensée. Il a maintenant plus de cinquante-trois centimètres et mange et digere une nourriture d'adulte.

La vraie difficulté vint di cote d'Hélène. Les femmes ne sont pas simple. Un rien de crottin les indispose. Ça les déséquilibre. Elles ne sont plus elles-mêmes.

“D'un si petit derrière lui disais-je, bien peu de crottin peut sortir", mais elle... Enfin, tant pis, il n'est plus question d'elle à présent.

Ce qui m'inquiète, c'est autre chose, ce sont tout d'un coup, certains jours, les changements étranges de mon petit cheval. En moins d'une heure, voilà que sa tête enfle, enfle, son dos s'incurve, se gondole, s'effiloche et claque au vent qui entre par la fenêtre.

\section{$\mathrm{Oh} ! \mathrm{Oh} !$}

Je me demande s'il ne me trompe pas à se donner pour cheval; car même petit, um cheval ne se déploie pas comme pas comme un pavillon, ne claque au vent fût-ce pour quelques instants seulement.

Je ne voudrais pas avoir été dupe, après tant de soins, après tant de nuits que j' ai passées à le veiller, le défendant des rats, des dangers toujours proches, et des fièvres du jeune âge. 
Parfois, il se trouble de se voir si nain. Il s'effare. Ou en proie au rut, il fait par-dessus les chaises des bonds enormes et il se met à hennir, à hennir désespérément.

Les animaux femmeles du voisinage dardent leur attention, les chiennes, les poules, les juments, les souris. Mais, c' est tout. "Non, décident-elles, chacune pour soi, collée à son instinct. Non, ce n'est pas à moi de répondre". Et jusqu à présent aucune femelle n'a répondu.

Mon petit cheval me regarde avec de la détresse, avec de la fureur dans ses deux yeux.

Mais, qui est em faute? Est-ce moi?

\section{Um Cavalinho}

Eu criei na minha casa um cavalinho. Ele galopa em meu quarto. É a minha distração.

No começo, eu tinha inquietações. Me perguntava se ele cresceria. Mas minha paciência foi recompensada. Ele tem agora mais de cinqüenta e três centímetros e come e digere uma comida de adulto.

A verdadeira dificuldade vem da parte de Hélène. As mulheres não são simples. Um pouco de excremento as indispõem. Isso as desequilibra. Elas não são mais elas mesmas.

“De um traseiro tão pequeno, eu dizia a ela, muito pouco excremento pode sair", mas ela... Enfim, tanto pior... não se trata mais dela agora. 
O que me inquieta é outra coisa, são, de uma hora para outra, alguns dias, as mudanças estranhas do meu cavalinho. Em menos de uma hora, de repente sua testa incha, incha, seu dorso se arqueia, se curva, se desfia e bate ao vento que entra pela janela.

\section{$\mathrm{Oh} ! \mathrm{Oh} !$}

Eu me pergunto se ele não se faz passar por um cavalo; porque mesmo pequeno, um cavalo não se hasteia como uma bandeira, nem bate ao vento, ainda que por alguns instantes somente.

Eu não queria ter sido um tolo, depois de tantos cuidados, de tantas noites que passei ao seu lado, defendendo-o de ratos, dos perigos sempre próximos, e das febres da tenra idade.

Às vezes, ele se atormenta em se ver tão anão. Ele se assusta. Tomado pelo cio, ele salta por cima das cadeiras em grandes saltos e relincha, relincha desesperadamente.

As fêmeas da vizinhança prestam atenção, as cadelas, as galinhas, as jumentas, as ratazanas. Mas é só isso. "Não, decidem elas, cada uma, segundo seu instinto. Não, não cabe a mim responder". E até hoje nenhuma fêmea respondeu.

Meu cavalinho me olha com aflição, com fúria em seus dois olhos.

Mas, de quem é a culpa? É minha? 


\section{Remarques}

Le rêve vient après une journée où ayant fait avec succès et enthousiasme des lithographies, je vois s'ouvrir devant moi d'immenses possibilités.

Charges d'émotions, charges de rêves.

La nuit en fut grosse, don't un décrit précédemment et celui-ci ensuite.

Ayant été impressionné par mon nouveau pouvoir d'action, dans le premier rêve je me représentais em lion. Ayant eu une impression $\mathrm{d}$ 'avenir, le deuxième rêve me montre um horizon devenu immense, là ou était un lieu resserré. Horizon, avenir. Lac. Étendue d'eau. Étendue sans efforts, où avancer va tout seul, est un pur plaisir. Et cette étendue, là où je ne l'attendais pas, dans une rue latérale médiocre, dans un quartier par excellence un endroit fixe, definitive, fermé, celui de la place de l'Ópéra, centre et coffre de la capitale, par ou l'on passe si souvent, quotidien immuable où on de puvait espérer aucun élargissement.

En fait, après quelques semaines, finie l'extension. En allé, l'enthousiasme. Plus d'horizon nouveau. Même en rêve. Paris a perdu son lac. 


\section{Observações}

O sonho vem depois de um dia em que havia feito litografias com sucesso e entusiasmo, vejo se abrirem diante de mim imensas possibilidades.

Cargas de emoção, cargas de sonhos.

A noite foi cheia de sonhos, dos quais um descrito anteriormente e este agora.

Impressionado pelo meu novo poder de ação, no primeiro sonho me representei como um leão. Com uma impressão de futuro, o segundo me mostrou um horizonte imenso, onde havia um lugar estreito. Horizonte, futuro. Lago. Extensão de água. Extensão sem esforço, onde avançar por si mesmo é um puro prazer. E esta extensão estava lá onde eu não a esperava, numa rua lateral medíocre, num bairro por excelência fixo, definitivo, fechado, aquele da Praça da Ópera, centro e cofre da capital, por onde se passa com tanta freqüência, cotidiano imutável no qual não se podia esperar nenhum alargamento.

De fato, depois de algumas semanas, acabou a expansão. Foise o entusiasmo. Nada de novo horizonte. Mesmo em sonho. Paris perdeu seu lago. 
Le temps plus propice pour naître n'était pas

n'est pas aujourd'hui

La Tour de la Mort s'élève se voit déjà de partout n'aura pas sa pareille

En un cercle, un cercle immensément large des cycles s'achèvent Des victimes sans tarder, seront là, présents. Simultanéité toujours si remarquable des sacrifiés et des armés.

O tempo mais propício para nascer não era não é hoje

A Torre da Morte se ergue já se vê de todos os lugares não haverá semelhante

Em um círculo, um círculo imensamente amplo ciclos acabam Vítimas estarão lá, sem tardar, presentes. Simultaneidade sempre tão notável dos sacrificados e dos armados. 